\title{
Schwannoma of the Ulnar Nerve at Distal Humerus: A Case Report
}

\author{
Konstantinos Ditsios*, Ioannis Theodoroudis, Nikolaos Papadakis, Lazaros Kostretzis, Panagiotis \\ Konstantinou and Anastasios Christodoulou
}

First Department in Orthopaedics and Trauma Surgery, Aristotle University of Thessaloniki, Greece

Submission: May 09, 2017; Published: May 25, 2017

*Corresponding author: Konstantinos Ditsios, Assistant Professor, First Orthopaedic Department, Aristotle University of Thessaloniki, G.Papanikolaou General Hospital, Exohi, GR 57010 Thessaloniki, Greece, Email: ditsiosk@otenet.gr

\begin{abstract}
We report a case of a female patient that presented in our outpatient department with notable muscle weakness in her right arm during the last year. Careful clinical examination revealed a palpable mass on the medial side of the right distal humerus with positive tinel sign and paresthesias along the ulnar side of her forearm. Magnetic resonance imaging showed a soft-tissue mass with 3.8 X $2.4 \mathrm{~cm}$ size possibly emerging from the right ulnar nerve just proximal to the elbow joint. Excisional biopsy confirmed the diagnosis of a rare type of ulnar's nerve schwannoma. Histologically the mass consisted of typical Antoni A areas with no signs of axon differentiation, whereas the immune histo chemistry examination revealed Schwann cell origin. Fourteen months post-operatively the patient has no motor weakness or paraesthesias and is very satisfied with the outcome.
\end{abstract}

Keywords: Case report; Humerus; Schwannoma; Ulnar nerve

\section{Introduction}

Schwannoma is the most common benign tumor primarily arising from the neural sheath of the peripheral nerves and composed of Schwann cells. Although the overall frequency in adults is $5 \%$ upper limb schwannomas constitute $19 \%$ of them [1,2]. Usually they appear as solitary lesions $[3,4]$ but occasionally can have multiple locations (schwannomatosis) or can be associated with neurofibromatosis, Additionally, rarely undergo malignant transformation [3-5]. The percentage of schwannomas that include the median nerve is about $7 \%$, when other nerves like as ulnar and peroneal are involved with various rates [6]. Clinical examination often reveals a palpable soft tissue mass along the course of the involved nerve that could be mobile at the longitudinal plane but not at the transverse plane [7]. Sometimes positive Tinel sign and paraesthesias at the distribution of the involved nerve [8] can be found, if the affected nerve is a sensory nerve or a mixed nerve.

\section{Case Report}

A 28 year old woman presented with a soft-tissue mass at the ulnar side of her distal right humerus. Clinical examination revealed an approximately $4 \mathrm{~cm}$ sized painless solid mass, pressure sensitive and firmly attached to the surrounding tissues. Slight percussion over the mass produced positive Tinel sign. The patient experienced mild numbness at the distribution of the ulnar nerve at the palm but no motor weakness or muscle atrophy were detected. Despite the large period of the mass existence (17 months) the patient remained asymptomatic. Significant enlargement and concomitant paraesthesias were observed during the latest 8 months. No history of significant trauma was recalled.

Magnetic resonance imaging (MRI) examination revealed a mass measuring about $33.9 \times 21.4 \times 15.4 \mathrm{~mm}$ in the medial side of the right distal humerous, well circumscribed in close proximity to the ulnar nerve, with low to intermediate intensity on T1weighted images and high intensity on T2-weighted images. No peri-tumoral edema was present and a line of fat surrounded the tumor. In addition nerve conduction studies showed pathological findings regarding the ulnar nerve.

Based on the long history of the patient, and the clinical MRI features the resection of the tumor was decided. A longitudinal incision centered over the tumor bulk was performed (Figure 1). The ulnar nerve was preserved and a tumor which was attached with the nerve was detected. The full excision of the tumor was accomplished and tissue for biopsy was sent for the final diagnosis (Figure 2). Histopathological examination included hematoxylin and eosin staining and immunohistochemistry for S-100 protein and neurofilamment. Histologically, the tumor consisted of varying hypertrophic peripheral nerve fascicules showing a plexiform pattern, along with fibrous connective 


\section{Orthopedics and Rheumatology Open Access Journal}

tissues. The tumor was mainly composed of Antoni A areas that consisted of dense fascicular and interlacing proliferation of spindle-shaped tumor cells without notable nuclear atypia.

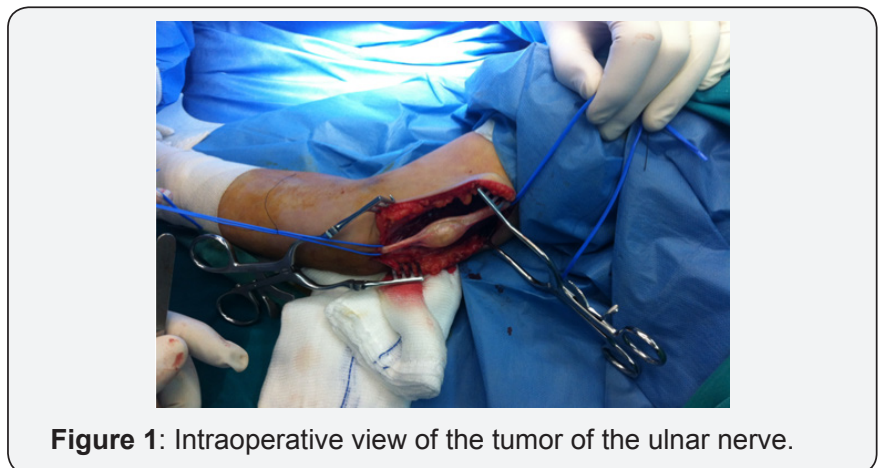

Figure 1: Intraoperative view of the tumor of the ulnar nerve.

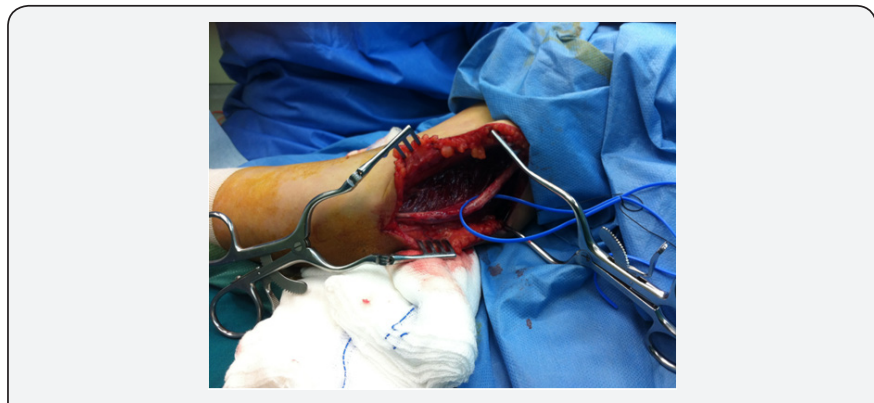

Figure 2: Intraoperative view of the ulnar nerve after full excision of the tumor.

A nuclear palisading pattern was focally observed in the tumor. Typical Antoni B areas were also observed in the tumor. Expression of S-100 was found in some of the cytoplasm. SMA, desmin and CD117 tests were all negative. CD34 was positive only for the vascular endothelial cells. The Ki-67 proliferation index was less than $2 \%$. Morphologically, the tumor consisted of typical Antoni A and Antoni B areas, which are generally found in schwannomas but not in neurofibromas, and immunohistochemistry results revealed a Schwann cell origin of the tumor cells. These features established the diagnosis of schwannoma. At the first postoperative day the patient had a numbness of the ulnar nerve distally of the excision but no motor defects. At 6 months follow up the wound is well healed with no tenderness upon palpation. No motor deficit is observed. The patient returned to full labor work as a lawyer and is satisfied with the outcome.

\section{Discussion}

Schwan cell tumors can remain for a long time asymptomatic especially when the patient can not feel the tumor or are able to produce numbness with a positive Tinel sign and sensory disturbances [6]. Donner et al. [8] pointed that there was no nerve action transmission through the tumour via these fascicles, suggesting that division of the affected fascicles will not induce neurological deficit. Recent studies [9-13] proved that 75-83\% of patients had immediate neurological deficit after excision of the tumor, due to the transection of fascicles that run through it. On histological analysis, a schwannoma has a true capsule composed of epineurium. A Schwann cell tumor is diagnosed by the alternating pattern of Antoni A and B areas [11]. Antoni A is cellular areas with spindle cells and nuclear palisading forming Verocay bodies whereas Antoni B is hypocellular areas in a myxoid background.

MRI findings regarding the morphology and signal intensity features reflect the histological components of schwannomas. A rim of low intensity surrounds the lesion corresponding to the epineural capsule [12]. Antoni A areas are cellular areas containing collagen, thus exhibiting low signal in T1 and T2 images. Water content in the myxoid matrix of Antoni B areas produces a low in $\mathrm{T} 1$ and high signal intensity in $\mathrm{T} 2$ images 12]. In conventional schwannomas, central location of the Antoni A areas produces the so-called target sign on T2 images.

Two types of schwannomas have been described. The first type involves well-encapsulated tumors in which they can be completely shelled out during the excision. The second one refers to tumors with fascicular involvement. So a functional deficit may result with the tumor removal. At present, there has not yet been a reliable method to predict the presence of fascicular involvement into the tumor including preoperative MRI. Tang et al. [14] proposed an algorithm in combination with the use of intraoperatively electrical stimulations to assess involvement of fascicles. In conclusion, schwannoma is an uncommon tumor with a reported predilection over the distal upper limb, a finding which might be explained by the fact that tumors at these sites are easier to be noticed or palpated by the patient. It occurs more in the mixed nerves instead of pure sensory or motor nerves.

\section{Conflict of Interest}

No conflicts of interest were declared by the authors.

\section{References}

1. Forthman CL, Blazar PE (2004) Nerve tumors of the hand and upper extremity. Hand Clinics 20(3): 233-242.

2. Das Gupta TK, Brasfield RD, Strong EW, Hajdu SI (1969) Benign solitary schwannomas (neurilemomas). Cancer 24(2): 355-366.

3. Gonzalvo A, Fowler A, Cook RJ, Little NS, Wheeler H, et al. (2011) Schwannomatosis, sporadic schwannomatosis, and familial schwannomatosis: a surgical series with long-term follow-up. Clinical article. J Neurosurg 114(3): 756-762.

4. Tanabe K, Tada K, Ninomiya H (1997) Multiple schwannomas in the radial nerve. J Hand Surg Br 22(5): 664-666.

5. Woodruff JM, Selig AM, Crowley K, Allen PW (1994) Schwannoma (neurilemoma) with malignant transformation. A rare distinctive peripheral nerve tumor. Am J Surg Pathol 18(9): 882-895.

6. Knight DM, Birch R, Pringle J (2007) Benign solitary schwannomas: a review of 234 cases. J Bone Joint Surg Br 89(3): 382-387.

7. White NB (1967) Neurilemomas of the extremities. J Bone Joint Surg Am. 49: 1605-1610.

8. Donner TR, Voorhies RM, Kline DG (1994) Neural sheath tumors of major nerves, Journal of Neurosurgery. 81(3): 362-373. 
9. Park MJ, Seo KN, Kang HJ (2009) Neurological deficit after surgical enucleation of schwannomas of the upper limb. J Bone Joint Surg Br 91(11): 1482-1486

10. Ogose A, Hotta T, Morita T, Yamamura S, Hosaka N, et al. (1999) Tumors of peripheral nerves: correlation of symptoms, clinical signs, imaging features, and histologic diagnosis. Skeletal Radiol 28(4):183-188.

11. Weiss SW, Goldblum JR, Enzinger FM (2001) Benign tumours of the peripheral nerves. In: Weiss S, Goldblum JR, Enzinger and Weiss's soft tissue tumours. St Louis Mosby, USA, pp. 1111-1208.
12. Isobe K, Tominaga S, Tsutomu A, Akahane T (2004) Imaging of ancient schwannoma. Am J Radiol 183(2): 331-336.

13. Adani R, Tarallo L, Mugnai R, Colopi S (2014) Schwannomas of the upper extremity: analysis of 34 cases. Acta Neurochir (Wien) 156(12): 2325-2330.

14. Tang CYK, Fung B, FokM, Zhu J (2013) Schwannoma in the upper limbs. Biomed Res 2013: 1-4.

\section{Your next submission with Juniper Publishers will reach you the below assets}

- Quality Editorial service

- Swift Peer Review

- Reprints availability

- E-prints Service

- Manuscript Podcast for convenient understanding

- Global attainment for your research

- Manuscript accessibility in different formats

( Pdf, E-pub, Full Text, Audio)

- Unceasing customer service

Track the below URL for one-step submission https://juniperpublishers.com/online-submission.php 